\title{
Central and peripheral contributions to physical and electrical fatigue
}

\author{
Omyma Galal, Anwer Said, Eman M Khedr*, Manal Abd-elsameea \\ Department of Physiology, Neurology* Assiut University Hospital, \\ Assiut, EGYPT.
}

\begin{abstract}
Background: fatigue has long been attributed to peripheral mechanism within the motor units, however, the stimulus for muscular contraction is initiated in the brain and therefore central fatigue may occur. This study aimed to investigate central and peripheral contributions to muscle fatigue, immediately and 20 minutes after physical and electrical fatigue in 25 healthy male volunteers.

Methods: physical fatigue was induced by sustained voluntary contraction of the first dorsal interossus muscle (FDI) lasted 10 minutes or till fatigue developed. While electrical fatigue was induced by transcutaneous electrical stimulation with trains of submaximal, 100- $\mu$ s pulses at $20 \mathrm{~Hz}$ for 3 minutes. Resting motor threshold, input-out put curve, motor evoked potential, cortical silent period duration, interference pattern of the right FDI and M/F ratio of ulnar nerve, all were recorded before, immediately and 20 minutes after test of fatigue.

Results: resting motor threshold, cortical silent period were significantly increased and input output curve was significantly suppressed immediately after physical fatigue. The reverse was observed after electrical fatigue. The amplitude of interference pattern and the envelope were significantly reduced immediately after physical fatigue. The same results were recorded after electrical fatigue. Almost all these changes returned nearly to baseline value 20 minutes after fatigue.

Conclusion: Central inhibition was recorded after physical fatigue while some cortical facilitation was proofed after electrical fatigue. However, peripheral inhibition was observed after physical and electrical fatigue. These changes return nearly to the base line 20 minutes after rest.
\end{abstract}

\section{INTRODUCTION}

Muscle fatigue can be defined as any reduction in the force-generating capacity of the total neuromuscular system which could be attributed to multifactorial causes and varies with the intensity and duration of the exercise, fiber type of the muscle and degree of training ${ }^{(1)}$. Fatigue has long been attributed to peripheral mechanism within the motor units which involves reductions in the ability of the muscle to perform work because of impairment anywhere along the chain of commands from neuromuscular transmission to actinmyosin cross bridges. This may be due to depletion of some necessary substances and or the accumulation of catabolites or other substances sets free by the muscle activity ${ }^{(2)}$. 
However, the stimulus for muscular contraction is initiated in the brain and therefore central fatigue may occur if alteration within the CNS decreases neural derives ${ }^{(3)}$. The most direct evidence of central fatigue has been generated through the use of a new technique, transcranial magnetic stimulation (TMS). Through TMS cortical excitability can be measured, and the decrease in post fatigue motor evoked potential gave a direct evidence of inhibition of central derives after fatigue ${ }^{(\mathbf{1})}$. As yet, the relative contribution of central and peripheral factors still clearly unexplored. This study was designed to examine whether the central and peripheral contribution to muscle fatigue were silimilar after physical and electrical fatigue in healthy male volunteers.

\section{SUBJECTS \& METHODS}

Twenty-five healthy physically fit, right handed adult male subjects with age range from 20-30 years were allocated in this study.

Exclusion criteria: Smokers, subjects had medical history of chronic illness, peripheral vascular disease or any neuromuscular disease. Subjects taking medications affecting muscle contraction are also excluded. They were randomly divided into 2 groups:

14 subjects submitted to physical fatigue of the right first dorsal interosseus muscle (FDI) and 11 subjects submitted to electrically induced fatigue of the FDI muscle by repeated electrical stimulation of the ulnar nerve at wrist.

\section{Electrophysiological tests and muscle} recording:

All tests were carried out on the right FDI which was chosen for this study because of its strong corticospinal projection $^{(4)}$. The action of FDI is abduction of the index finger, flexion of the metacarbopharyngeal (MCP) joint, and extension of the inter-pharyngeal joint of the index finger ${ }^{(5)}$. Each subjects sat comfortably in a chair with his right hand and forearm supported. The middle to little fingers was secured with a strap so that only the index finger can be contributed to force production.

Muscle recording: of electrical signals associated with muscle activity was done by using surface electrodes for recording EMG reactions from the right FDI muscle; the recording electrode was placed on the muscle belly and the other at the MCP joint of the index finger, the ground electrode was placed at the wrist. The recording of muscle response was done with the Dantec Keypoint TM device.

Experimental protocol: At the beginning of each experiment, the resting motor threshold, motor evoked potential (MEP) amplitude, inputoutput curve and cortical silent period duration were determined for all subjects by using transcranial magnetic stimulation device (TMS). The interference pattern parameters of the right FDI were recorded by using the EMG equipment. Additionally the amplitude of ulnar nerve F-wave and M-wave responses were calculated. Immediately after fatigue test as quickly as possible all previous series of parameters were measured again, 
also, 20 minutes later all the parameters were repeated for the third time.

Transcranial magnetic stimulation (TMS) of the motor cortex:

Single- pulse TMS of $70 \mu \mathrm{s}$ duration was applied over the scalp by a stimulator Dantec Keypoint Medtronic mode (Copenhagen, Denmark) with a figure-of-eight stimulating coil (the outer diameter of each coil wing is $9 \mathrm{~cm}$ ) over the area of the left motor cortex that was optimal for producing motor evoked potentials (MEPs) in the right FDI, the coil was placed tangential to skull over the vertex contra-lateral to the muscle, so that the zero line corresponded to the vertex $(0,0)$. The coil oriented so that currents was induced in a posterior to anterior direction in the left motor cortex, and fine adjustments of position was done to identify the optimum location 'hotspot' for evoking EMG reactions from the FDI of each subject (6 and 7). Once the optimal site was identified, the site was marked with a red dot to ensure consistency of stimulation during the experiment. This coil location was maintained fixed by manual handling throughout the TMS procedure. The TMS intensities are routinely expressed as a percentage of the maximum stimulator output. Stimuli were delivered as single shocks at least 5-10 seconds apart.

\section{The resting Motor threshold} determination:

The resting motor threshold is defined as the lowest stimulator output at which five MEPs with minimum peak-to-peak amplitude of $50 \mu \mathrm{V}$ were evoked from the resting FDI in ten consecutive trials ${ }^{(8)}$. The resting motor threshold intensity was determined by asking the participants to remain immobile and fully relax their hand to ensure that full relaxation was maintained during this set of recordings. MEPs were recorded only when the EMG indicated that the right FDI was inactive. Trials in which EMG activity was present were immediately rejected. Then, adjusting the stimulator output, the cortex was initially stimulated at $25 \%$ of maximum coil output. Intensity was gradually increased with 5 stimuli given at each intensity until a $50 \mu \mathrm{V}$ (in amplitude) signal was produced on 5 out of 10 trials.

\section{MEP amplitude:}

The MEPs evoked in the resting right FDI by using stimulation intensity $130 \%$ of the resting motor threshold with 5 stimuli given to elicit 10 MEPs. The mean of peak-to-peak amplitude of these MEPs evoked were determined.

\section{An input-output curve:}

An input-output curve for the MEP amplitude evoked in the resting right FDI by TMS was constructed by using stimulation intensity $110 \%$, $120 \%, 130 \%, 140 \%$ and $150 \%$ of motor threshold. The peak-to-peak amplitude of these MEPs evoked at previously mentioned stimulus intensity was determined. The amplitudes of the MEP averages were plotted against stimulus intensity in each subject, and the cortical stimulus-response curves of each subject were constructed.

\section{Cortical silent period:}

The cortical silent period was elicited while the subjects maintained a steady voluntary abduction of the 
right index finger; magnetic stimuli were delivered over the optimal motor cortex hand area (the same scalp position as for producing MEPs). The intensity of the magnetic stimulus was adjusted to $130 \%$ of the resting motor threshold. Ten trials for cortical silent period were recorded with an intertrial interval of approximately $5 \mathrm{~s}$ with the stimulus intensity being kept constant. The duration of the silent period is the time from stimulus to the return of voluntary EMG activity. For analysis, the duration of the silent period was measured by cursor and the average duration of these 10 values calculated for each subject.

Interference pattern (IP) of the right FDI:

Electrodes were first placed on right FDI muscle then the subject was asked to maximally open a binder clip with his index and thumb finger, interference pattern is the EMG recording during maximum voluntary contraction of FDI. In complete interference pattern the baseline is obscured completely by motor unit activity. Interference pattern analysis include peak-to-peak amplitude of IP and the average amplitude (envelop) as well as the number of turns/second were recorded.

\section{$M$ /F ratio of ulnar nerve:}

The electrode connections for eliciting $\mathrm{M}$ and $\mathrm{f}$ waves from ulnar nerve consist of a pair of stimulating electrodes in addition to the recording electrodes and the ground electrode. Stimulation was made over the ulnar nerve on the medial aspect of the wrist. The ulnar nerve stimulation was used for evoking compound muscle action potential (CMAP) also referred to as "M-wave" or "M-response" recorded from FDI by the EMG machine.

The stimulus intensity was set to more than 1.25 times the value needed for maximum $\mathrm{M}$-wave amplitude (supra-maximum stimulation) ${ }^{(\mathbf{9})}$. Supramaximal electrical stimulation of the ulnar nerve at the wrist was done for each subject with simultaneous recording of (M-wave) and F-wave (The F-wave is the late muscular response following the $\mathrm{M}$ wave) from right FDI muscle.

Because different anterior horn cells are activated at different times, the shape and latency of F-waves are different from one another so, ten to twenty F-waves and M-waves were obtained and the mean of the following parameters were evaluated for both the M and F- waves: latency, peak-to-peak amplitude, duration and $\mathrm{M}$-wave amplitude to $\mathrm{F}$-wave amplitude ratio ( $\mathrm{M} / \mathrm{F}$ ratio).

\section{Fatigue test}

Fatigue was induced in FDI with physical activation or electrical stimulation as following:

The physical fatigue was induced by sustained voluntary contraction of (FDI). Each subject was asked to open a binder paper clip positioned in front of them with the extended index finger against the thumb finger and pushing on the ears of the clip as strongly as possible to open it until the edges of the clip became away from each other by $10 \mathrm{~mm}$ distance measured against a fabric tape length measure. Subjects received continuous visual feedback and verbal encouragement throughout the fatigue test and ensure that the subject was performing the prescribed task to try to maintain the distance opened. 
Each subject performed this sustained voluntary contraction of the FDI using his maximal effort lasted $10 \mathrm{~min}$ or till fatigue developed. Some subjects developed fatigue manifestation before $10 \mathrm{~min}$, which manifested as a feeling of burning inside a muscle, cramping, pain, weakness, tremors and inability to maintain the contraction (inability to maintain the edges of the clip more than or equal $5 \mathrm{~mm}$ ). Then fatigue test was followed by relaxation.

The binder clip used is " FEI YI binder clip- China” N: 0003, outer width is $11 / 4$ inch $(32 \mathrm{~mm})$ the force required to open the clip $10 \mathrm{~mm}, 5$ $\mathrm{mm}$ that was measured in the department of mechanics in the faculty of Engineering Assiut university by using mechanical force gauge. To ensure that the binder clip resistance was not changed thoughtout the study the force required to open the clip for $10 \mathrm{~mm}$ distance was measured again with the mechanical force gauge after 5 successive fatigue experiments done by 5 subjects and also at the end of the study all measures was the same as the first measure.

The electrical fatigue was done by electrical stimulation of the motor point; a cathode was placed over the ulnar nerve at the wrist. Fatigue was induced by transcutaneous stimulation with trains of supramaximal, $100-\mu \mathrm{s}$ pulses at frequency $20 \mathrm{~Hz}$. for 3 minutes. The intensity of electric stimulation was adjusted to be slightly above the electric motor threshold of FDI and resulted in a just visible contraction in FDI. This stimulation intensity was adjusted so as to decrease the pain resulting from the electric stimulation.

\section{Statistical analysis:}

The data of each group are tabulated in the Microsoft Excel 97 program from the master sheet giving a serial number for each subject then statistical analysis was performed by using the program SPSS for Windows version 9.0.0, SPSS, 1989-19999. Results are calculated as the following:

1) Data are expressed as Arithmetic mean \pm Standard deviation (SD) and the data range.

2) For each group paired two tailed Student's “ $t$ " test was used to compare values of varias parameters tested pre and post fatigue, the Differences were considered statistically significant when $\mathrm{P}$ values were less than or equal 0.05 .

\section{RESULTS}

Assessment of resting motor threshold, before, immediately and 20 minutes after physical fatigue shows that the mean value of resting motor threshold (\% of maximum stimulator output) was significantly increased immediately after fatigue $(\mathrm{P}=0.031)$ then it returned to the initial values 20 minutes after rest $(\mathrm{P}=0.921)$, while there were no such changes observed after electrical fatigue (table 1).

MEP amplitude $(\mathrm{mV})$ at $130 \%$ of the resting motor threshold was significantly depressed immediately after physical fatigue $(\mathrm{P}$ value $=0.006)$ then it returned to pre-fatigue value $(\mathrm{P}$ value $=0.509) 20$ minutes after rest. Whereas in electrically induced fatigue there was an increased in MEP amplitude immediately after fatigue 
$(\mathrm{P}=0.011)$, then after 20 minutes rest the amplitude decrease again to reach the pre-fatigue level (table 1)

Cortical silent period duration (ms) was significantly prolonged immediately after physical fatigue test $(\mathrm{P}$ value $=0.021)$, then regain nearly to the initial value 20 minutes after rest $(\mathrm{P}=0.828)$. In electrical induced fatigue group although the mean value of cortical silent period duration decreased immediately after fatigue test but it statistically insignificant $(\mathrm{P}$ $=0.175)$, then it returned nearly to the initial value 20 minutes after rest $(\mathrm{P}=$ 0.245) (table 1).

Concerning the input out-put curve, a decrease in the slope of the of input-out-put curve with shift to the right immediately after physical fatigue. While, in electrically induced fatigue there was increase in MEP response to different TMS intensities and there was an increase in the slope of the curve with shift to the lift immediately after fatigue (figure 1\&2)

There was insignificant change of turns /second either immediately or 20 minutes after physical fatigue. While the amplitude of interference pattern $(\mu \mathrm{v}) \quad$ reduced significantly immediately after physical fatigue ( $P$ $=0.019$ ), and almost returned nearly to baseline value 20 minutes after rest $(\mathrm{P}=0.13)$. A significant reduction in the amplitude of envelope $(\mu v)$ was observed immediately after fatigue ( $\mathrm{P}$ $=0.0005), 20$ minutes after rest the mean value of the amplitude of envelope significantly increased again $(\mathrm{P}=0.0014)$, but still less than the pre fatigue value ( $\mathrm{P}=0.023)$ (table 2 ).

In electrical induced fatigue, turns per second decreased immediately after fatigue test however, the difference between the two values did not reach a statistical significant value $(\mathrm{P}=0.103)$. Then it returned nearly to the baseline value 20 minutes after rest. A significant reduction in the amplitude of interference pattern $(\mu \mathrm{v})$ was found immediately after fatigue $(\mathrm{P}=0.0002)$, and partially returned to the prefatigue value after 20 minutes rest. The amplitude of envelope ( $\mu \mathrm{v})$ decreased significantly immediately after fatigue test $(P=0.0004)$, and returned to the baseline value after 20 minutes of rest (table 2).

In physical fatigue group, the mean values of $M$ wave amplitude (mv) was significantly decreased immediately after fatigue $(\mathrm{P}$ value $=$ 0.0 .029 ) and returned to the prefatigue value 20 minutes after fatigue. The same was observed after electrically induced fatigue. In both groups the $\mathrm{M}$ $/ F$ ratio was not significantly altered immediately after fatigue or 20 minutes after rest. 
Table 1: Central contribution to physical and electrical muscle fatigue

\begin{tabular}{|c|c|c|c|}
\hline & $\begin{array}{c}\text { Before fatigue } \\
\text { test }\end{array}$ & $\begin{array}{c}\text { immediately after } \\
\text { fatigue test }\end{array}$ & $\begin{array}{l}20 \text { minutes after } \\
\text { fatigue test }\end{array}$ \\
\hline $\begin{array}{l}\text { Resting motor threshold (\% of } \\
\text { maximum stimulator output) } \\
\text { Physical fatigue } \\
\text { Electrical fatigue }\end{array}$ & $\begin{array}{c}41.07 \pm 7.69 \\
(28-57) \\
41.45 \pm 9.48 \\
(25-57) \\
\end{array}$ & $\begin{array}{c}43.5 \pm 9.61^{*} \\
(31-65) \\
41.64 \pm 10.88 \\
(22-60) \\
\end{array}$ & $\begin{array}{c}41.14 \pm 7.79 \\
(30-57) \\
41.09 \pm 9.42 \\
(24-55) \\
\end{array}$ \\
\hline $\begin{array}{l}\text { Motor evoked potential (mV) } \\
\text { Physical fatigue } \\
\text { Electrical fatigue }\end{array}$ & $\begin{array}{l}1.77 \pm 1.69 \\
(0.5-5.5) \\
1.22 \pm 0.67 \\
(0.2-2.2) \\
\end{array}$ & $\begin{array}{c}0.89 \pm 0.9 * * \\
(0.2-3.5) \\
1.85 \pm 1.12^{*} \\
(0.1-3.5) \\
\end{array}$ & $\begin{array}{c}1.69 \pm 1.6 \\
(0.4-5) \\
1.29 \pm 0.71 \\
(0.1-2.3) \\
\end{array}$ \\
\hline $\begin{array}{l}\text { Cortical silent period (ms) } \\
\text { Physical fatigue } \\
\text { Electrical fatigue }\end{array}$ & $\begin{array}{c}122.07 \pm 37.77 \\
(54-171) \\
128.74 \pm 42.51 \\
(85.5-228)\end{array}$ & $\begin{array}{c}135.43 \pm 44.41^{*} \\
(83-238) \\
118.85 \pm 42.91 \\
(63.5-219)\end{array}$ & $\begin{array}{c}120.93 \pm 35.44 \\
(65-168) \\
120.44 \pm 41.74 \\
(88.2-232) \\
\end{array}$ \\
\hline
\end{tabular}

Data are expressed as mean \pm SD $\quad$ ( ) Range $\quad *$ : P value $<0.05 \%$ by paired $t$ test

**: $\mathrm{P}$ value $<0.01 \%$ by paired t test

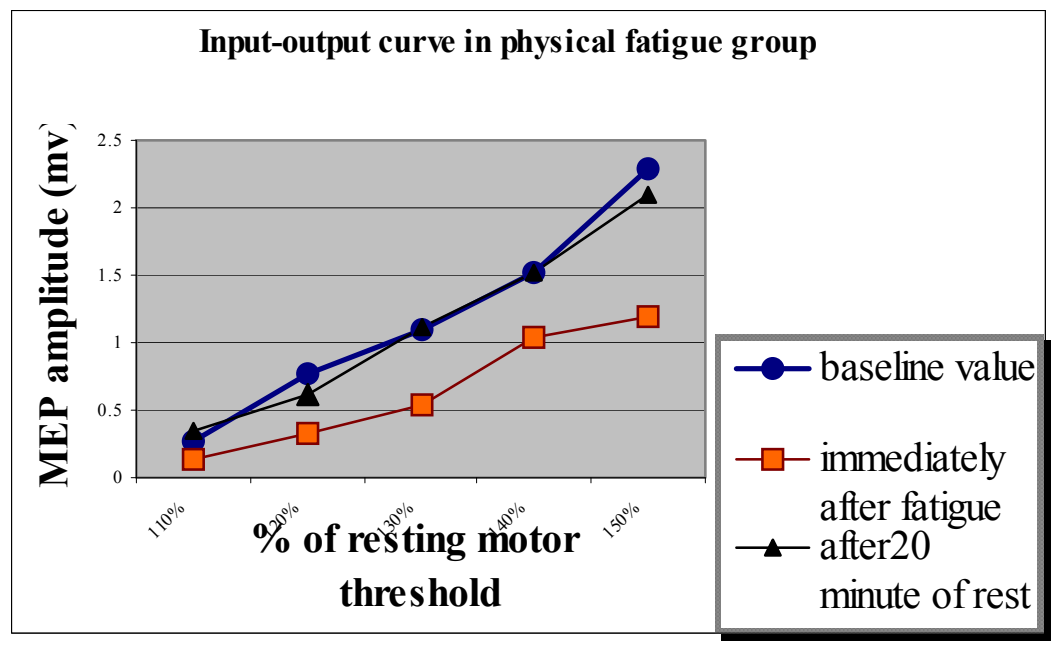

Figure (1) 
Table 2: Peripheral contribution to physical and electrical muscle fatigue

\begin{tabular}{|c|c|c|c|}
\hline & $\begin{array}{c}\begin{array}{c}\text { Before fatigue } \\
\text { test }\end{array} \\
\end{array}$ & $\begin{array}{c}\text { immediately after } \\
\text { fatigue test }\end{array}$ & $\begin{array}{c}20 \text { minutes after } \\
\text { fatigue test }\end{array}$ \\
\hline $\begin{array}{l}\text { Turns/ second } \\
\text { Physical fatigue } \\
\text { Electrical fatigue }\end{array}$ & $\begin{array}{l}292.93 \pm 62.39 \\
(217-411) \\
280.82 \pm 91.47 \\
(110-397) \\
\end{array}$ & $\begin{array}{c}286.43 \pm 57.14 \\
(153-366) \\
245 \pm 60.62 \\
(145-340)\end{array}$ & $\begin{array}{l}292.64 \pm 58.75 \\
(189-378) \\
265.45 \pm 85.07 \\
(110-401) \\
\end{array}$ \\
\hline $\begin{array}{l}\text { Amplitude of interference } \\
\text { pattern }(\boldsymbol{\mu} v) \\
\text { Physical fatigue } \\
\text { Electrical fatigue }\end{array}$ & $\begin{array}{c}1652.36 \pm 1029.22 \\
(805-4797) \\
1233.91 \pm 357.82 \\
(770-1784)\end{array}$ & $\begin{array}{c}926.86 \pm 335.11^{* * *} \\
(538-1818) \\
846.45 \pm 414.76^{* * *} \\
(420-1698)\end{array}$ & $\begin{array}{c}1191.21 \pm 374.31 \\
(622-2007) \\
1190.64- \pm .421 .35 \\
(532-1822)\end{array}$ \\
\hline $\begin{array}{l}\text { Envelop of interference } \\
\text { pattern }(\boldsymbol{\mu v}) \\
\text { Physical fatigue } \\
\text { Electrical fatigue }\end{array}$ & $\begin{array}{l}3618.64 \pm 884.83 \\
(2167-4999) \\
2925.46 \pm 1108.37 \\
(1504-4739) \\
\end{array}$ & $\begin{array}{c}2425.71 \pm 910.23 * * * \\
(1311-4746) \\
1940.64 \pm 852.53 * * * \\
(890-3612) \\
\end{array}$ & $\begin{array}{c}2994.07 \pm 765.83 * \\
(1878-4920) \\
2731.36 \pm 1134.6 \\
(1117-4571) \\
\end{array}$ \\
\hline $\begin{array}{l}\text { Amplitude of CMAP (mv) } \\
\text { Physical fatigue } \\
\text { Electrical fatigue }\end{array}$ & $\begin{array}{c}18.93 \pm 4.28 \\
(9.5-25.5) \\
15.48 \pm 6.82 \\
(4.4-23.6) \\
\end{array}$ & $\begin{array}{l}16.46 \pm 6.12 * \\
\quad(4-24.2) \\
11.78 \pm 6.25^{*} \\
(3-22.4)\end{array}$ & $\begin{array}{c}17.88 \pm 5.31 \\
(7.9-26.6) \\
13.54 \pm 5.38 \\
(4-22) \\
\end{array}$ \\
\hline $\begin{array}{l}\text { M/F ratio } \\
\text { Physical fatigue } \\
\text { Electrical fatigue }\end{array}$ & $\begin{array}{c}67.05 \pm 53.21 \\
(19.14-190) \\
63.96 \pm 33.58 \\
(23.25-119)\end{array}$ & $\begin{array}{c}68.82 \pm 52.64 \\
(22.5-200) \\
55.81 \pm 31.37 \\
(23-111)\end{array}$ & $\begin{array}{c}73.96 \pm 67.48 \\
(8.33-200) \\
77.8 \pm 64.01 \\
(20-204)\end{array}$ \\
\hline
\end{tabular}

Data are expressed as mean $\pm \mathrm{SD}$ ( ) Range

*: $\mathrm{P}$ value $<0.05 \%, * *$ : $\mathrm{P}$ value $<0.01 \%$, ,**: $\mathrm{P}$ value $<0.001$ by paired t test

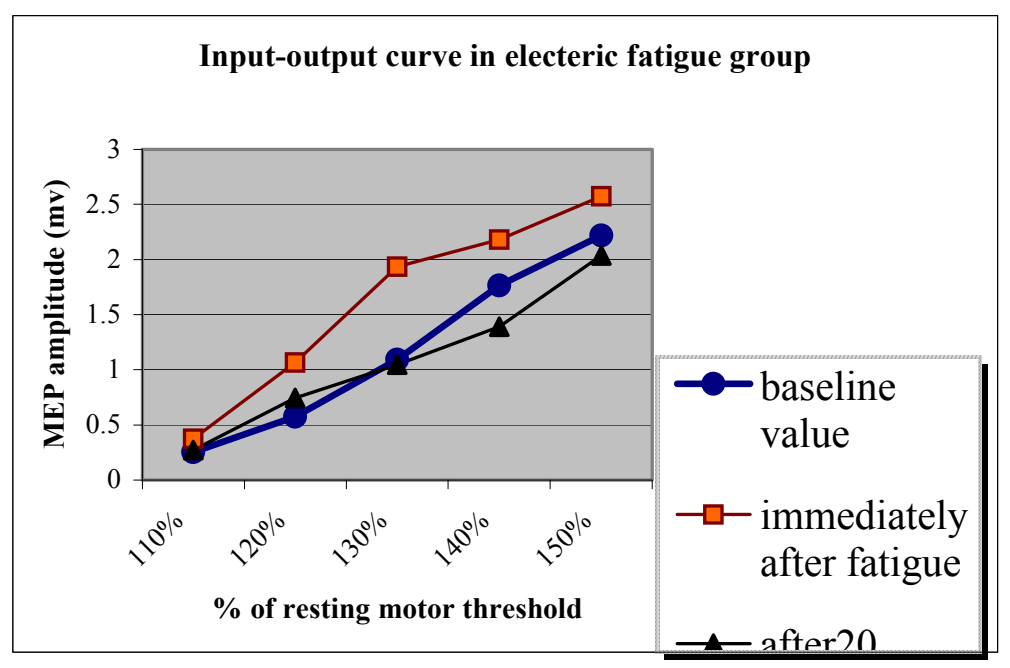

Figure 2 


\section{DISCUSSION}

This study was designed to examine whether the central and peripheral contribution to muscle fatigue were similar after physical and electrical fatigue

\section{I- Central contribution to physical} and electrical fatigue:

In the present study cortical inhibition was recorded immediately after physical fatigue and return nearly to prefatigue state 20 minutes after while the reverse was observed after electrical fatigue. These results documented by the significant increase of resting motor threshold, decrease MEP, suppression of inputoutput curve, and increase of cortical silent period duration, following physical fatigue while the reverse was observed after electrical fatigue.

Resting motor threshold was measured as index of corticospinal excitability $^{(\mathbf{1 0})}$. RMT has been proposed to represent a marker of membrane excitability in the pyramidal output cells, because it is relatively insensitive to pharmacological manipulations involving neurotransmission ${ }^{(\mathbf{1 1 , 1 2})}$. In the present study, the increased RMT as well as the decreased MEP, following physical fatigue may be related to change in membrane excitability. This means that corticospinal excitability for FDI muscle can be modulated by physical fatigue this finding is in agreement with previous studies showing that physical fatigue capable of producing inhibition in corticospinal excitability ${ }^{(\mathbf{3 , 1 3} \& 4)}$. This was supported a decrease in the slope of the of input- out-put curve with shift to the right immediately after fatigue this result together with the depression in MEP amplitude observed in this study may be due to intracortical inhibition. Intracortical inhibition (ICI) is likely due to increase the activity of inhibitory GABAergic interneurons. $\gamma$ -Aminobutyric acid (GABA) is the most important inhibitory neurotransmitter in the cortex and drugs that enhance GABA increase ICI as tested by paired $\mathrm{TMS}^{\mathbf{( 1 2 )}}$. In physical fatigue group cortical silent period (SP) prolonged in duration immediately after fatigue then, silent period elicited 20 minutes after rest recovered to the initial value. (14) found that cortical silent period was prolonged with continued muscle contraction and ${ }^{(\mathbf{1 5})}$ reported that cortical silent period prolonged in duration immediately after intermittent isometric maximal fatiguing contraction of elbow flexors in nine healthy subjects. ${ }^{(16)}$ found that silent period duration lengthened by $55 \mathrm{~ms}$ in twenty four healthy subjects after a sustained $50 \%$ maximum voluntary contraction then decrease rapidly. Prolongation of the silent period reflects a balance at the corticofugal cell between local intracortical inhibition and excitation evoked by the stimulus and excitation derived from volition ${ }^{(\mathbf{1 7 )}}$, and thus could be caused by a net increase in intracortical inhibition associated with the stimulus and/or reduced voluntary drive to the cortical output cell ${ }^{(\mathbf{1 8})}$.

Changes in SP duration reflect changes in central inhibition. This central inhibition may be at spinal level that contribute to the initial 
electromyography silence, or may be due to reduced cortical output that may be responsible for the later part of the $\left.\mathrm{SP}^{(19} \& 20\right)$. In healthy subjects, this cortical inhibition contributing to the later part of SP produced by cortical stimulation following voluntary fatiguing contraction seems to be related to focal changes within the activated motor cortex and reflects a net increase in inhibition to corticospinal cells. However, during fatigue changes in spinal excitability appear not to be responsible for the increase in SP duration ${ }^{(21)}$. In this study the prolongation of the duration of the silent period (SP) following TMS as fatigue develops means that increased inhibition within the cortex resulted in decreasing the ability to produce muscle force.

All these changes suggest postexercise depression of cortical excitability. This "post-exercise depression" has been cited by others $^{(\mathbf{6 , 2 2 \& 2 3})}$ as evidence of central fatigue following exhaustive exercise. Contrary to this, ${ }^{(4)}$ reported that in twelve healthy volunteers resting motor threshold was not altered before or after physical fatigue of FDI difference in result probably due to differences in the duration of exercise protocol to induce fatigue, in the study of $^{(4)}$ the duration of exercise was 2 minutes while in our study it was 10 minutes.

There are a number of possible sites at which fatigue-related changes could act to reduce cortical excitability. These include neural pathways projecting to the motor cortex, the cortex itself, corticospinal neurons, and spinal motoneurons ${ }^{(4)}$. (13) Showed that, immediately after a 2-min maximal voluntary elbow flexion, the excitability of corticospinal axons is reduced. However, this change was recovered within 2 minutes of cessation of contraction and was facilitated thereafter, whereas MEPs remained depressed for many minutes. Thus, although this factor may contribute to the initial phase of post-contraction MEP amplitude depression, it does not persist and is not the primary cause.

In the present study the $\mathrm{F}$ waves response which considered a reliable marker of spinal motoneuron excitability $^{(24)}$ did not change after fatigue so depressed MEPs observed after physical fatigue in this study could not result from reduction of spinal motoneuronal excitability.

In electrical induced fatigue the value of resting motor threshold did not change significantly before, immediately after fatigue or 20 minutes after fatigue, this result agree with that of ${ }^{(4)}$ who reported that following electrically induced fatigue of FDI of twelve volunteers resting motor threshold was not changed.

In the present study MEP was facilitated after electrical fatigue and recovered to prefatigue values after 20 minutes, an observation that is in agreement with ${ }^{(\mathbf{2 5})}$ who reported that 10 minutes of high-intensity pharyngeal stimulation increased the excitability of the pharyngeal cortex. (4) Reported that MEP amplitudes in human hand muscle are depressed during voluntary fatigue but initially facilitated when fatigue is induced with electrical (motor point) stimulation. This facilitation persists for $\sim 20 \mathrm{~min}$. 
Although this finding, there was several studies ${ }^{(26} \&$ 27) have reported that cortical facilitation is induced by nonfatiguing electrical stimulation of mixed peripheral nerves. Thus the observation that the MEPs were facilitated after motor point stimulation is consistent with the possibility that the muscle contraction elicited by motor point stimulation depressed the excitability of the motor cortex but that this was masked by the facilitation induced by the afferent stimulation.

In electrical induced fatigue the cortical silent period duration did not change significantly before or after fatigue but there was a tendency to be decreased.

In electrically induced fatigue there was increase in MEP response to different TMS intensities and there was an increase in the slope of the curve with shift of the input-output curve to the lift immediately after fatigue. This result together with the increase in MEP amplitude found in our study indicate enhanced response after electric fatigue which may be due to intracortical facilitation.

As the voluntary fatigue induced depression of cortical excitability and electrical stimulation induced facilitation of cortical excitability implies that the electrical stimulation activates one or more classes of afferents that either is not activated by or are less affected by the voluntary fatigue protocol, these inputs facilitate the motor cortex ${ }^{(4)}$. This intra-cortical facilitation after the electric fatigue in this study may be employed for motor rehabilitation, in particular, those with notable decreases in excitability such as those with patients with stroke.

\section{II- Peripheral contribution to physical and electrical fatigue:}

In the present study peripheral inhibition was recorded immediately after physical and electrical fatigue. The significant decrease of amplitude of interference pattern, turns/second and envelop as well as suppression of CMAP amplitude immediately after fatigue confirm the peripheral inhibition after physical and electrical fatigue.

The significant reduction in the amplitude of interference pattern, amplitude of the IP envelope and turns per second of interference pattern immediately after physical and electrical fatigue tests and recovery toward the baseline value after $20 \mathrm{~min}$ indicate that the initial muscle force could not be maintained by the subjects at the end of the fatigue this means decrease in FDI force as a consequence of the fatiguing contraction. Changes in muscle force can occur from rather variation in modulating the rate at which action potentials drive active motor units (discharge rate) or in the number of motor units recruited ${ }^{(\mathbf{2 8})}$. The modulation of discharge rate appears to be variable and to depend upon the intensity and duration of the fatiguing contraction. The discharge rate of the motor units has been observed to decrease progressively in the study of $^{(29)}$ for low-threshold $(<25 \%$ MVC of FDI) motor units whereas it show initial increase for high- threshold (> $25 \%$ MVC of FDI) motor units. The inability of some motor units to discharge continuously in the presence of sustained central drive has been observed during maximal contractions $^{(30)}$. 
The decrease force recorded by EMG may, however, occur with incomplete effort of muscle contraction, possibly contributed to localized pain experienced by most of the participants of this study after either fatigue protocol.

It is well known that group III and IV afferent activity progressively increases during fatigue due to release of metabolic products which may inhibits the motoneuron pool via reflex circuitry ${ }^{(31 \& 32)}$.

The central mechanisms potentially involved in the decrease of firing rate during pain may be due to inhibition of spinal motoneurons ${ }^{(33)}$. Alternative interpretation is the possibility of conscious changes in the neural drive, subjects may reacted to the muscle pain by a voluntary change of control strategy, aimed at the decrease of the activity of the different muscles contributing to the contraction $^{(34)}$.

In physical fatigue group the mean value of $\mathrm{M}$ wave amplitude was significantly lower immediately after fatigue but it had recovered 20 minutes later. The pattern of contractile failure occurs with reduction in $\mathrm{M}$ wave, indicating an impairment of the muscle membrane excitability or neuromuscular propagation or transmission failure that may have contributed to the inability to sustain the voluntary task. However, it is important to note that a decline in peripheral transmission interferes with voluntary and evoked potentials recorded using surface electromyography ${ }^{(35)}$. This reduction in $\mathrm{M}$ wave is in consistency with that reported by (4 and 35). They found that M-wave amplitude decreased immediately after the voluntary fatigue, but it recovered to prefatigue levels 20 min later in twelve healthy volunteers. However in the study of ${ }^{(36)}$ they used short-term high intensity fatigue 60-s MVC in the adductor pollicis, there was no change in $\mathrm{M}$ wave amplitude before or after fatigue this difference may be due difference in duration, degree of fatigue and on the intrinsic properties of the individual muscle.

In electrically induced fatigue, $M$ wave amplitude was significantly reduced; 20 minutes later it showed partial recovery which was consistent with the results of ${ }^{(4)}$. ${ }^{(37)}$ reported that decreased amplitude of M-waves were significant after high-frequency electrical fatigue $(80-\mathrm{Hz})$ in tibialis anterior and soleus muscles.

Physiological events that may contribute to $\mathrm{M}$ wave failure include axonal branch point failure, neuromuscular junction failure or a reduction in the amplitude of the sarcolemmal action potential ${ }^{(38} \&$ 39). Branch point and neuromuscular junction failure would both result in a reduction in the force-producing capacity of the motor unit. A decline in the sarcolemmal action potential can occur without changes in fiber activation in some animal models; however, there is evidence to suggest that it could result in incomplete activation of mammalian fast-twitch units $^{(39)}$.

The F-wave is a late muscular response due to backfiring of spinal a -motoneurons during maximal stimulation of peripheral nerve motor fibers, the F-wave can be considered a reliable marker of spinal motoneuron excitability $^{(24)}$. There was no 
significant change in F- wave latency, F-wave amplitude; also the $\mathrm{M} / \mathrm{F}$ ratio was not altered at any time either after physical fatigue or electrical induced fatigue.

Our results on F-wave indicate that no changes in the excitability of spinal motoneuronal are taking place after fatigue at the spinal level; this is in line with the study of ${ }^{(40)}$ they found that the magnitude of $F$ waves elicited by median nerve stimulation in the APB muscle remained unchanged. ${ }^{(4)}$ Found that the electrical stimulation till fatigue in ulnar nerve did not alter F-wave amplitude, whereas in fatigue following physical exercise in the same study F wave amplitude decreased.

\section{CONCLUSIONS}

The results of this study indicate that immediately after physical fatigue reduced cortical excitability was recorded in the form of increase in resting motor threshold, depression of MEP size, reduction of input output curve and prolongation of cortical silent period. These results indicate that central inhibition and central fatigue alter cortical excitability without altering spinal excitability (no significant change in-F wave). However, some cortical facilitation was recorded after electrical fatigue demonestrated by increase of MEP size and of input output curve with tendency of cortical silent period to decrease.

This implies that the electrical stimulation activates one or more classes of afferents which facilitate the motor cortex these afferents either is not activated by or are less affected by the voluntary fatigue test. These afferents are not yet identified.

The peripheral inhibition and peripheral fatigue was observed after both types of fatigue (physical and electrical) detected by decrease in $M$ wave amplitude indicating a decrease in muscle membrane excitability and reduction in the parameters of the interference pattern of the EMG.

The central and peripheral changes that immediately recorded after both types of fatigue recovered nearly to the base line 20 minutes after rest.

\section{RECOMMENDATIONS}

1- Further experimental paradigms should be developed to detect the relative and quantitative contribution of central and peripheral mechanisms in muscle fatigue.

2- Other muscles as muscles of the lower limb or trunk muscle need to be studied as regard the mechanism of fatigue, also other exercise protocols should be considered changing the duration (short or prolonged) and the type of of fatiging contraction (intermittant or sustained, maximal or submaximal).

3- Futher work is recommended upon central and peripheral mechanisms of fatigue in patiants at whom muscle fatigue is a major and is most disabling symptom including multiple sclerosis, myasthenia gravis, post-poliomyelitis, post-stroke, chronic fatigue syndrome and in Parkinson's disease hopefully new medical treatments for the 
symptom will be made available. Additionally the study of fatigue in these diseases may provide an opportunity to further describe the symptom clinically and to understand and decide its pathogenesis.

4- As the electeric fatigue cause cortical facilitation so this type of intervention, which increase the excitability of the cortex, can be recommended for motor rehabilitation, in particular, those with notable decreases in excitability such as those with patients with stroke.

\section{REFERENCES}

1- Gandevia, S. C. (1998): Neural control in human muscle fatigue: changes in muscle afferents, motoneurones and motor cortical drive. Acta Physiologica Scandinavica; 162, 275-283.

2- Kirkendall, D. T. (1990): Mechanisms of peripheral fatigue. Med. Sci. Sports Exercise; 22: 444-449.

3- Kent-braun, J.A. (1999): Central and peripheral contributions to muscle fatigue in humans during sustained maximal effort. Eur. J. Appl. Physiol. Occup. Physio; 80: 5763.

4- Pitcher, J.B. and Miles, T.S. (2002): Alterations in corticospinal excitability with imposed vs. voluntary fatigue in human hand muscles. J Appl Physiol; 92: 2131-2138.

5- Woodburne, R.T. and Burkel, W.E (1999): Essentials of Human Anatomy. 9th ed. Oxford,
UK: Oxford University Press; 1999.

6- Brasil-Neto, J.P.; McShane, L.M.; Fuhr, P.; Hallet, M. and Cohen, L.G. (1992): Topographic mapping of human motor cortex with magnetic stimulation. Factors affecting accuracy and reproducibility. Electroencephalogr Clin Neurophysiol; 85:9-16.

7- Rossi, S.; Pasqualetti, P.; Tecchio, F.; Sabato, A. and Rossini, P.M. (1998): Modulation of corticospinal output to human hand muscles following deprivation of sensory feed-back. NeuroImage ; 8:163175.

8- Kujirai, T.; Caramia, M.D.; Rothwell, J.C.; Day, B.L.; Thompson, P.D. and Ferbert, A. (1993): Corticocortical inhibition in human motor cortex. J Physiol; 471: 501-19.

9- Zijdewind, I.; Zwarts, M.J. and Kernell, D. (2000): Potentiating and fatiguing cortical reactions in a voluntary fatigue test of a human hand muscle. Exp Brain Res; 130: 529-532.

10- Davey, N.J.; Puri, B.K.; Catley, M.; Main, J.; Nowicky, A.V. and Zaman, R. (2003): Deficit in motor performance correlates with changed corticospinal excitability in patients with chronic fatigue syndrome. Int $J$ Clin Pract; 57(4): 262-4.

11- Mavroudakis, N.; Caroyer, J.M.; Brunko, E. and Zegers de Beyl, D. (1994): Effects of diphenylhydantoin on motor potentials evoked with magnetic 
stimulation. Electroencephalogr Clin Neurophysiol; 93: 428-33

12- Ziemann, U.; Lönnecker, S.; Steinhoff, B.and Paulus, W. (1996): Effects of antiepileptic drugs on motor cortex excitability in humans: a transcranial magnetic stimulation study.Ann Neurol; 40: 367-78.

13- Gandevia, S.C.; Petersen, N.; Butler, J.E. and Taylor, J.L. (1999): Impaired response of human motoneurones to corticospinal stimulation after voluntary exercise. J. Physiol. 521: 749-759.

14- Ljubisavljevic, M.; Milanovic, S. and Radovanovic, S. (1996): Central changes in muscle fatigue during sustained submaximal isometric voluntary contractionas revealed by transcranial magnetic stimulation.

Electroencephalography and clinc neurophysiology;101:281-8.

15- Taylor, J.L.; Allen, G.M.; Butler, J.E. and Gandevia, S.C. (2000): Supraspinal fatigue during intermittent maximal voluntary contractions of the human elbow flexors. $J$ Appl Physiol; 89: 305-313,

16- Andersen, B.; Westlund, B. and Krarup, C. (2003): failure of activation of spinal motor neurons after muscle fatigue in healthy subjects studied by transcranial magnetic stimulation.J physiolo 5551,1:345-356.

17- Von Giesen, H.J.; Roick, H. and Benecke, R. (1994): Inhibitory actions of motor cortex following unilateral brain lesions as studied by magnetic brain stimulation. Exp Brain Res; 99: 84-96.

18- Gandevia, S. C. (2001): Spinal and Supra-spinal Factors in Human Muscle Fatigue Physiol. Rev; 81: 1725-1789.

19- Fuhr, P.; Agostino, R. and Hallett, M. (1991): Spinal motor neuron excitability during the silent period after cortical stimulation. Electroencephal Clin Neurophysiol; 81:237-62.

20- Inghilleri, M.; Berardelli, A.and Cruccu, G. (1993): Silent period evoked by transcranial stimulation of the human cortex and cervicomedullary junction. $J$ Physio; 466:521-34.

21- Taylor, J.L.; Butler, J.E. and Allen, G.M. (1996): Changes in motor cortex excitability during human muscle fatigue. J Physiol; 490:519-28.

22- Samii, A.; Wassermann, E.M.; Ikoma, K.; Mercuri, B. and Hallett, M. (1996): Characterization of post-exercise facilitation and depression of motor evoked potentials to transcranial magnetic stimulation. Neurology 46:1376-1382.

23- Samii, A.; Wassermann, E.M. and Hallett, M. (1997): Postexercise depression of motor evoked potentials as a function of exercise duration. Electroencephalogr. Clin. Neurophysiol. 105 :352-356

24- Prahlow, N.D. and Buschbacher, R.M. (2003): An introduction to electromyography: an invited review. Long Term Eff Med Implants.;13(4):289-307. 
25- Hamdy,S.; Rothwell,J.C.;Aziz, Q.; Singh, K.D. and Thompson, D.G. (1998): Long-term reorganisation of human motor cortex driven by short term sensory stimulation. Nat Neurosci; 1:64-68.

26- Ridding, M.C; Brouwer, B.; Miles, T.S.; Pitcher, J.B. and Thompson, P.D. (2000): Changes in muscle responses to stimulation of the motor cortex induced by peripheral nerve stimulation in human subjects. Exp Brain Res; 131: 135-143.

27- Ridding, M.C.; Mckay, D.R.; Thompson, P.D. and Miles, T.S. (2001): Changes in corticomotor representations induced by prolonged peripheral nerve stimulation in humans. Clin Neurophysiol 112: 1461-1469.

28- Fuglevand, A.J.; Macefield, V.G. and Bigland-Ritchie, B. (1999): Force-Frequency and Fatigue Properties of Motor Units in Muscles That Control Digits of the Human Hand. $J$ Neurophysiol; 81: 1718-1729.

29- Carpentier, A.; Duchateau, J. and Hainaut, K. (2001): Motor unit behaviors and contractile changes during fatigue in the human first dorsal interosseus. Journal of Physiology; 534: 903912

30- Peter, E. J. and Fuglevand, A. J. (1999): Cessation of human motor unit discharge during sustained maximal voluntary contraction. Neuroscience Letters; 274:66-70.

31- Garland, S.J. (1991): Role of small diameter afferents in reflex inhibition during human muscle fatigue. J Physiol; 435: 547-558.

32- Farina, D.; Arendt-Nielsen, L.; Merletti, R. and GravenNielsen, T. (2004): Effect of Experimental Muscle Pain on Motor Unit Firing Rate and Conduction Velocity $J$ Neurophysiol; 91: 1250-1259,

33- Le Pera, D.; Graven-Nielsen, T.; Valeriani, M.; Oliviero, A.; Di Lazzaro, V.; Tonali, P.A. and Arendt-Nielsen, L. (2001): Inhibition of motor system excitability at cortical and spinal level by tonic muscle pain. Clin Neurophysiol; 112: 1633-1641.

34- Ciubotariu, A.; Arendt-Nielsen, L. and Graven-Nielsen, $T$. (2004): The influence of muscle pain and fatigue on the activity of synergistic muscles of the leg. Eur J Appl Physiol;45:44-51.

35- Kalmar, J.M. and Cafarelli, E. (2004): Central fatigue and transcranial magnetic stimulation: effect of caffeine and the confound of peripheral transmission failure. neuroscience; 138: 15-26.

36- Bigland-Ritchie, B.; Johansson, R. S.; Lippold, O. J.; Smith, S. and Woods, J. (1983): Changes in moto-neuron firing rates during sustained maximal voluntary contractions. $J$ of Physiology 340: 335-346

37- Badier, M.; Guillot, C.; Danger, C.; Tagliarini, F. and Jammes, Y. (1999): M-wave changes after high and low frequency electrically induced fatigue in different muscles. Muscle Nerve; 22(4):488-96. 
38- Sieck, G.C. and Prakash, Y.S. (1995): Fatigue at the neuromuscular junction. Branch point vs. presynaptic vs. postsynaptic mechanisms. Adv. Exp. Med. Biol;. 384: 83-100.

39- Fuglevand, A.J. (1995): The role of the sarcolemma action potential in fatigue. Adv. Exp. Med. Biol.; 384: 101-108.

40- Stefan, K.; Kunesch, E.; Cohen, L.G.; Benecke, R. and Classen, J. (2000): Induction of plasticity in the human motor cortex by paired associative stimulation, Brain, Vol. 123, No. 3, 572-584.

$$
\begin{aligned}
& \text { دور الآليات الطرفية والمركزية فى الإعياء العضلي }
\end{aligned}
$$

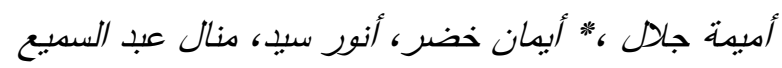

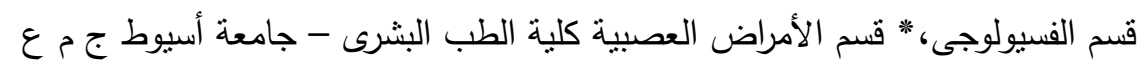

الأفراد والوسائل :هذه دراسة من خلال تعاون بين قسمى الفسيولوجى والأمراض العصبية بكلية الطب جامعة

$$
\text { أسيوط }
$$

اجرى هذا البحث على مجموعتين من الذكور البالغين الأصحاء وقد نم تقسيم الأفراد بشكل عشوائي إلى 
المجموعة الأولى : لدراسة إعياء العضلة الخلفية الأولى بين عظام اليد بعد أقصى إنقباض تباعدى إرادى محتمل لأصبع السبابة المجموعة الثَّانية : لدراسة إعباء العضلة الخلفية الأولى بين عظام اليد بعد إنقباض مستحث بثكل كهربائي

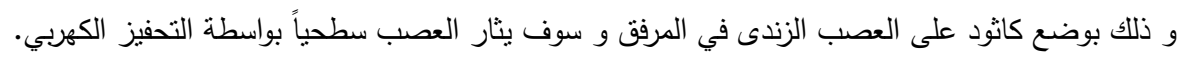
وقد تم دراسة مايلى لإظهار الإعياء الطرفي:

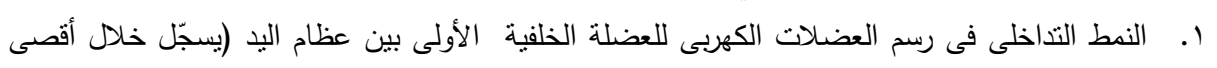
إنقباض).

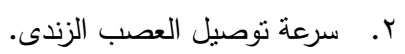

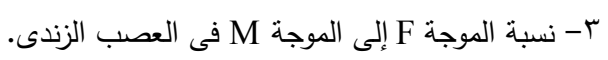

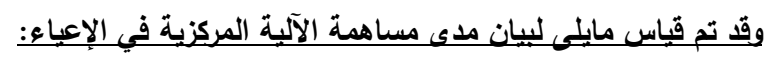

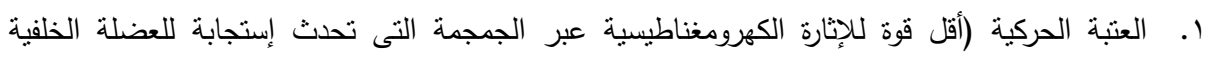

$$
\text { الأولى بين عظام اليد) }
$$

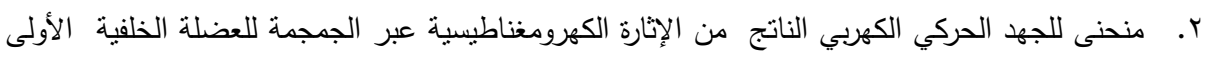

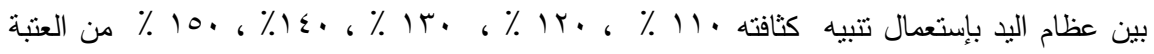

$$
\text { الحركية. }
$$

r. التثيط الناتج من القشرة المخية ويقاس بفترة السكون القترية.

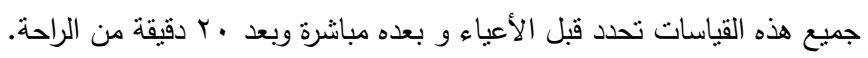

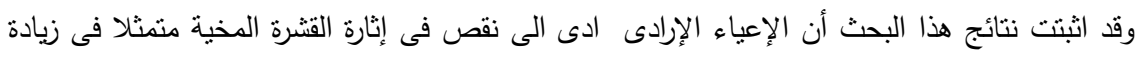

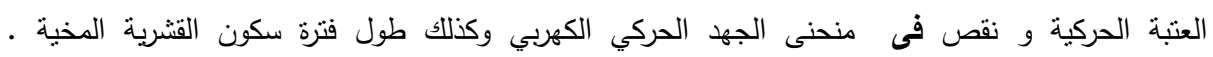

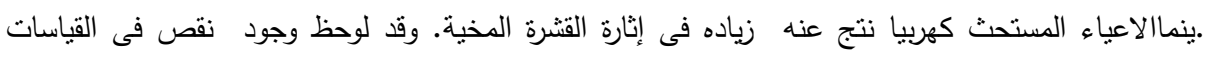

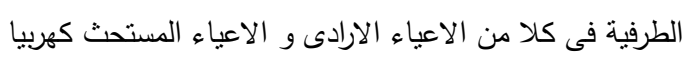

